\title{
LARGE-SCALE MONOTONIC AND CYCLIC TESTS OF INTERFACE BETWEEN GEOTEXTILE AND GRAVELLY SOIL
}

\author{
GA ZHANG ${ }^{\text {i) }}$ and JIAN-MIN ZHANG ${ }^{\text {ii) }}$
}

\begin{abstract}
A series of monotonic and cyclic shear tests, as well as pullout tests, were conducted on gravel-geotextile interfaces using a large-scale apparatus, with development of a new special pullout test element. The macroscopic response of stress and displacement, as well as the movement and crushing process of soil particles, were observed and measured. The interface exhibited evident strain-softening and aeolotropic normal displacement, which were significantly influenced by normal stress. Shear strength decreased and normal displacement increased with increasing number of shear cycles. Shear deformation was composed of slippage at the contact surface and deformation of the soil constrained by the geotextile; and the thickness was estimated at 5-6 times the average soil grain size. There was significant evolution of physical state due to shear application, including soil particle crushing and soil compression, as well as damage to the geotextile. The pullout test underestimated shear stiffness of the interface due to significant deformation of the geotextile itself. Shear strength increased with increasing normal stress, described by a logarithmic equation, according to the pullout tests, rather than the linear relationship obtained using direct shear tests. Therefore, an appropriate test method should be selected with careful consideration of the site conditions.
\end{abstract}

Key words: geotextile, gravelly soil, interface, monotonic and cyclic behavior, pullout test, shear test (IGC: D6/D7/E12)

\section{INTRODUCTION}

Geotextile is an effective and widely-used approach to improve engineering behavior of various earth structures. The static and dynamic response of soil-geotextile systems, due to various loads, may be significantly affected by monotonic and cyclic behavior of a soil-geotextile interface.

The direct shear test has been widely used to investigate the behavior of many kinds of soil-geotextile interfaces (Swan, 1987; Athanasopoulos, 1996; Saleh, 2001; Stoewahse et al., 2002; Abu-Farsakh et al., 2007). This type of test has been improved significantly in recent years, for example, the sample size can be maintained constant, and the slippage displacement at the interface can be separated using measurement of soil particle movements (e.g., Zhang et al., 2006). The major disadvantage of such a test is the stress concentration at the ends of the interface. The torsion ring test can maintain the strains nearly uniform within the specimen (Stark and Peoppel, 1994; Tan et al., 1998). However, difficulties in preparing specimens and measuring deformation preclude the torsion ring test from broad application, especially in practical projects.

The pullout test is another important means to examine a soil-geotextile interface (e.g., Fannin and Raju, 1993; Bakeer et al., 1998; Aiban and Ali, 2001; Lo, 2003; Long et al., 2007). This test allows for deformation of the geotextile, and so is closer to reality than shear tests. Whereas, stress and deformation of the interface are transferred progressively during the test and induces significant nonuniform deformation of the interface. The ramp test is often used to determine properties of soilgeotextile interfaces under small normal stress conditions (Lima et al., 2002; Ling et al., 2002; Gourc and Ramirez, 2004).

Strength behavior was emphasized in many monotonic and cyclic tests of a soil-geotextile interface (e.g., Lee and Manjunath, 2000); a few equations were therefore proposed to estimate interface strength (e.g., Geroud et al., 1993; Tan et al., 1995). Lo (2003) analyzed the influence of three-dimensional constrained dilatancy on the pullout resistance factor. The deformation behavior was also examined in tests (e.g., Aiban and Ali, 2001). Many tests were conducted on the influence factors of soilgeotextile interfaces (e.g., Eigenbrod et al., 1990; Saleh, 2001). The fabric geometry, geosynthetic structure, and soil particle size were shown to have important effects on shear strength (Swan, 1987; Lopes et al., 2001; Lima et al., 2002).

i) Ph.D, Associate Professor, State Key Laboratory of Hydroscience and Engineering, Tsinghua University, Beijing, P R China (zhangga@ tsinghua.edu.cn).

ii) Professor, ditto.

The manuscript for this paper was received for review on May 29, 2008; approved on November 27, 2008.

Written discussions on this paper should be submitted before September 1, 2009 to the Japanese Geotechnical Society, 4-38-2, Sengoku, Bunkyo-ku, Tokyo 112-0011, Japan. Upon request the closing date may be extended one month. 
Most available tests have focused on the strength behavior of the interface between a geotextile and sand/clay. However, the stress-strain behavior, for example, volumetric change due to cyclic shear, has not been investigated adequately. Moreover, the deformation mechanism has not been observed by microscopy, though there were similar studies on steel-type interface (Guler et al., 1999; Zhang and Zhang, 2006b). In addition, behavior of the interface between a geotextile and gravelly soil, which has larger grain size than sand, has not been systematically investigated. Such interfaces are a great concern because geotextile has been extended to many gravelly soil structures such as rockfill embankments, breakwaters, and speed-railways. The gravelly soil-type interface has different features to a sand-type interface, for example, such type of interface exhibits complex volumetric change due to dilatancy dependent on only a part of the tangential displacement and shear history (Zhang and Zhang, 2006b). Thus, further study is required on the monotonic and cyclic behavior of the interface between a geotextile and gravelly soil.

On the basis of serialized monotonic and cyclic test results of the interface between a steel and gravelly soil (Zhang and Zhang, 2006b), we conducted a series of large-scale tests on the interface between a geotextile and gravelly soil, including monotonic/cyclic direct shear and pullout tests, with observations on both the macro- and micro- responses. The objectives of this paper are: (1) to give a brief introduction of the tests including the apparatus, measurements, and materials; (2) to present typical test results in both macro- and micro- ways; and (3) to summarize and discuss the behavior and deformation mechanism of such an interface using test results.

\section{APPARATUS AND MEASUREMENTS}

The direct shear tests of the soil-geotextile interface were conducted using a large-scale apparatus, "TsingHua-20 tonne Cyclic Shear Apparatus for Soil-Structure Interface" (TH-20t CSASSI) (Figs. 1 and 2) (Zhang and Zhang, 2006a), which was developed especially to examine the monotonic and cyclic behavior of the interface between a gravelly soil and different kinds of structural materials such as geotextile, steel, and concrete. Any one of the three normal boundary conditions, namely constant stress, constant displacement, and constant stiffness, can be directly applied to the interface with a high degree of accuracy, via a modification of the soil container (Zhang and Zhang, 2006a). The structural material was designed with a larger size than the soil surface to ensure that the size of the interface was maintained during the test. A high load capacity up to $200 \mathrm{kN}$ was provided in both directions, tangential and normal to the interface, with automated control at various rates. A soil container (500 $\mathrm{mm}$ in length, $360 \mathrm{~mm}$ in width) was used for gravelly soil. Stresses and displacements of the interface, in both tangential and normal directions, were measured automatically using sensors with an accuracy of $0.1 \%$. The movement and crushing of soil particles was record-

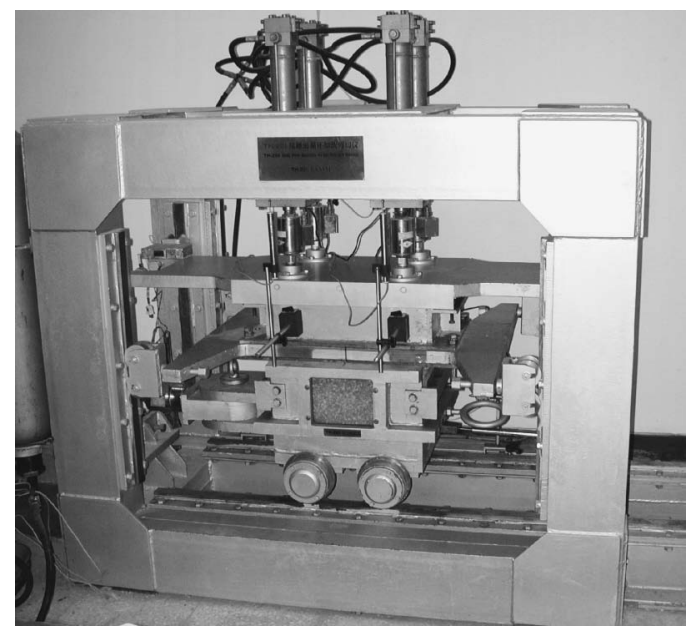

Fig. 1. Photograph of the test apparatus, TH-20t CSASSI

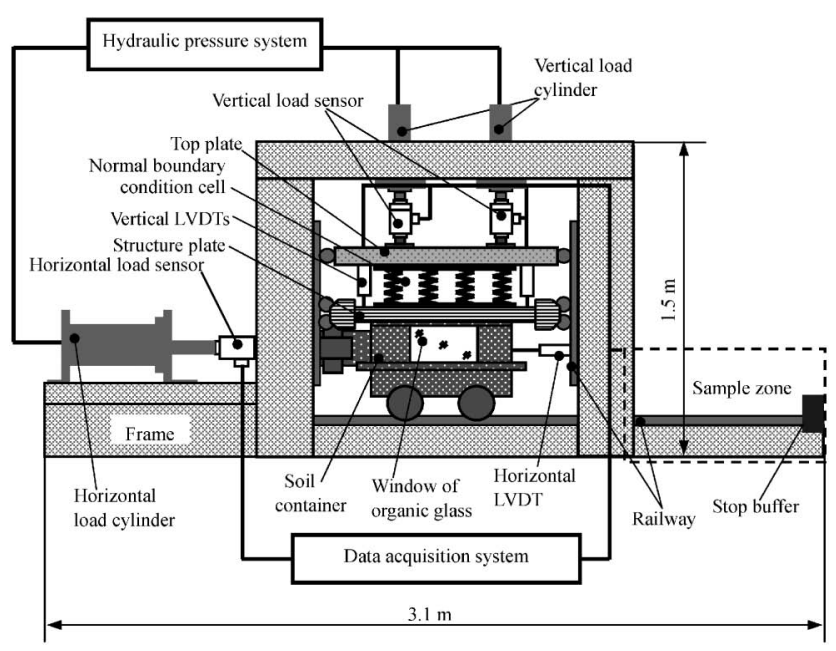

Fig. 2. Schematic view of construction of TH-20t CSASSI

ed by a high-resolution camera through a transparent lucite window within the soil container (Fig. 2). The lucite surface, close to the soil, was specially dealt with so that it is smooth decreasing the side friction between the window and soil particles. The movements of the particles were measured using a microscopic movement-measuring system, based on correlation-based image analysis theory, with sub-pixel accuracy (Zhang et al., 2006).

When conducting a shear test of a soil-geotextile interface, the geotextile was solidly adhered to the structure plate above the soil container. The soil sample was installed in the soil container and compacted to the required dry density in layers (Fig. 2). The soil-structure interface was therefore formed for tests. The constant normal stress boundary condition was directly applied to the interface and maintained by the normal boundary cell during the test. The container of soil was driven by the hydraulic pressure system to move horizontally without vertical movement so that a tangential displacement was realized. At the same time, the structure plate with geotextile was fixed in the horizontal direction but was able 


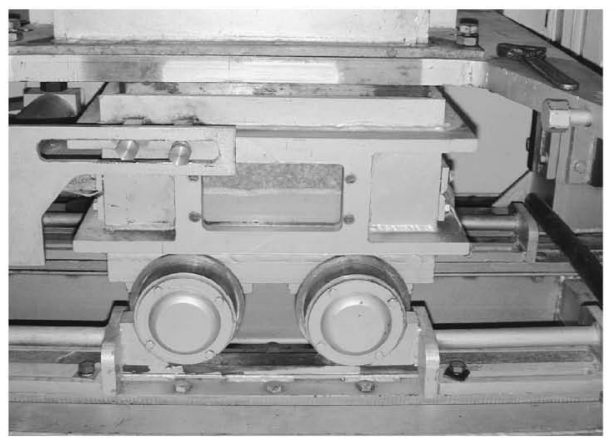

(a) photograph

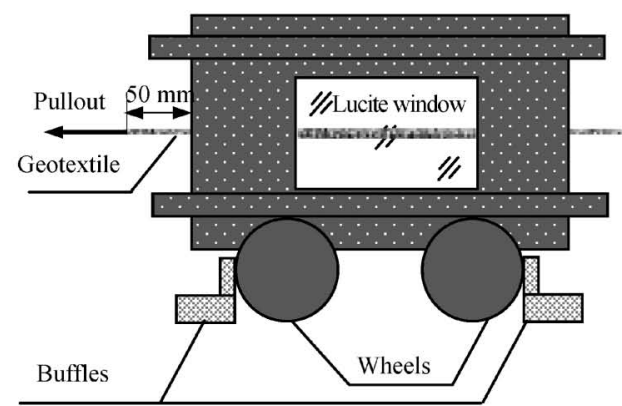

(b) structural view

Fig. 3. Container for pullout test on the basis of TH-20t CSASSI

to move freely in the vertical direction, thereby exhibiting the change of normal displacement.

For the TH-20t CSASSI, a new test container was developed for a large-scale geotextile pullout test (Fig. 3); its inner size is $450 \mathrm{~mm}$ in length, $360 \mathrm{~mm}$ in width, and $250 \mathrm{~mm}$ in height. A horizontal cut was made in the middle of the container, $360 \mathrm{~mm}$ in width, to place the geotextile; the thickness of the cut can be freely adjusted from 0 to $10 \mathrm{~mm}$ to accommodate different types of geotextiles. The geotextile was larger than the soil surface to ensure a constant contact size during the test. There was a thick lucite window in one side of the container (Fig. 3), through which the movements and crushing of soil particles were observed and recorded during testing. In pullout testing, the container was fixed to rails using specially designed baffles (Fig. 3). The constant normal boundary condition was applied on the soil surface via the plunger of the normal condition cell. The normal displacement of the interface was measured via that of the plunger. A special holding device was used to drag the geotextile in a horizontal direction via the horizontal hydraulic pressure system in the pullout test; the loading rate was adjusted according to the test requirements. It should be noted that there was $50 \mathrm{~mm}$ from the cut of the container to the load end of the geotextile; thus a $50 \mathrm{~mm}$ of geotextile did not make contact with the soil (Fig. 3). Loads and displacements of pullout tests were measured by the data acquisition system used in shear tests (Fig. 2).

\section{MATERIALS}

A type of nonwoven geotextile, made of nylon, was used in the tests, which was taken from the geotextile-reinforced cushion under a breakwater on soft ground of the Tianjin Huanghua Harbor, China. This type of geotextile is widely used in China and is approximately 1.3 $\mathrm{mm}$ in thickness. The average opening size of this geotextile, O50, is about $0.04 \mathrm{~mm}$; and $\mathrm{O} 95$ is about 0.15 $\mathrm{mm}$. The warp direction was used in the tests, with the tensile strength $100 \mathrm{kN} / \mathrm{m}$ and modulus $400 \mathrm{kN} / \mathrm{m}$ in this direction; the limit extensibility is $35 \%$.

A conglomerate gravel with very angular particles was used in the tests as a typical gravelly soil. A homogeneous

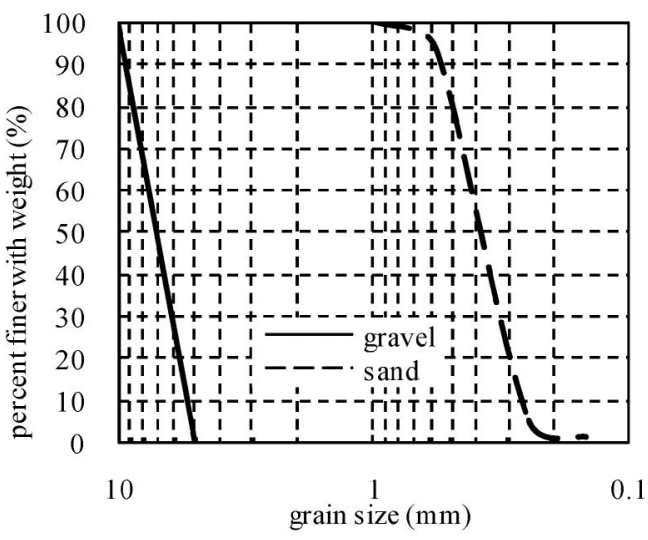

Fig. 4 Grain size distributions of soil

grain size distribution was used (Fig. 4) and the gravel dry density was $1.75 \mathrm{~g} / \mathrm{cm}^{3}$. This type of gravel was previously used in tests on a steel-gravel interface (Zhang and Zhang, 2006b). Triaxial compression tests indicated that the gravel dilated, $5 \%$ at the axial strain of $10 \%$, after a little compression, if the confining pressure was small, 0.1 $\mathrm{MPa}$; and it exhibited continuous compression, $2 \%$ at the axial strain of $10 \%$, if the confining pressure was large, $0.8 \mathrm{MPa}$ (Zhang and Zhang, 2006b). In addition, a type of quartz sand, with known grain size distribution (Fig. 4), was used in a few pullout tests; its relative density was controlled at $70 \%$.

The interface was $500 \mathrm{~mm}$ long and $360 \mathrm{~mm}$ wide for shear tests, and $450 \mathrm{~mm}$ long and $360 \mathrm{~mm}$ wide for pullout tests; these sizes were maintained invariable during tests. All tests were displacement controlled at a loading rate of $1 \mathrm{~mm} / \mathrm{min}$. The test conditions, such as the applied displacement and normal stress, were selected by considering the limit conditions of the geotextile reinforcement of earth structures.

\section{SHEAR TEST RESULTS}

Typical monotonic and cyclic test results of the gravelgeotextile interface are dissertated to discuss the behavior based on macro- and micro- measurements. Since both 


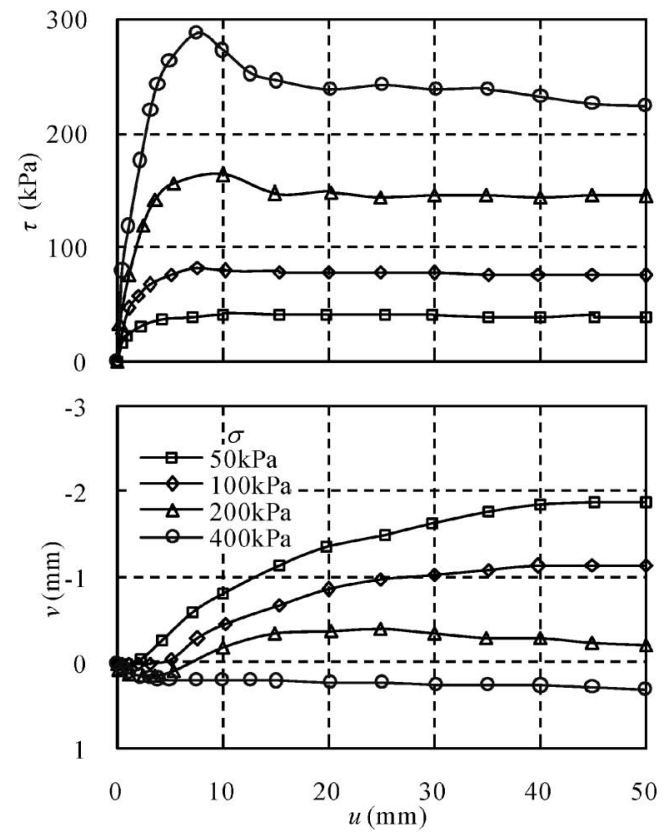

Fig. 5. Monotonic shear test results of the geotextile-gravel interface under constant normal boundary condition. $\tau$, shear stress; $\sigma$, normal stress; $u$, tangential displacement; $v$, normal displacement

sample size and normal stress were maintained constant during the shear test, the normal displacement was only induced by changes in shear stress or tangential displacement. Thus, it can be regarded as volumetric change due to dilatancy of the interface, defined as positive if the interface contracted and negative if dilated.

\section{Monotonic Stress-displacement Relationship}

Figure 5 shows the monotonic shear test results under constant normal stress condition. It can be seen that shear stress increased with monotonically increasing tangential displacement and reached a peak value, after which it slightly decreased. This indicated significant strain-softening due to shear application. The peak shear stress and initial slope of the tangential stress-displacement relationship curve both increased with increasing normal stress. In addition, the extent of strain-softening also increased with increasing normal stress. For example, strain-softening was negligible if normal stress was $50 \mathrm{kPa}$, but was significant when normal stress increased to $400 \mathrm{kPa}$ (Fig. 5). This strain-softening behavior differed significantly from a steel-gravelly soil interface, which exhibited insignificant strain-softening due to shear application (Zhang and Zhang, 2006b), though the gravel was the same for both interfaces. Moreover, this also differed significantly from that of a steel-sand interface, where strain-softening extent decreased with increasing normal stress (Uesugi and Kishida, 1986). Strain-softening can be attributed to damage to the geotextile induced by gravel friction during shearing. In other words, the surface behavior of the geotextile changed due to shear application and increasing normal stress significantly exacerbated this change. This was confirmed by observations of breakage of the geotextile after shear tests under

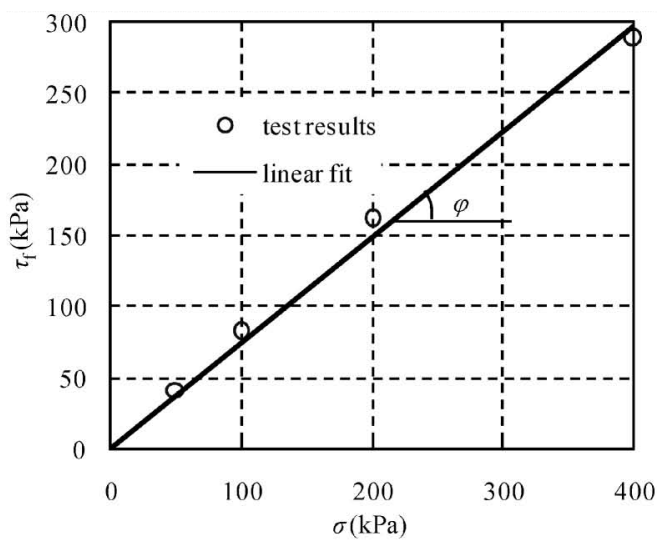

(a) peak strength

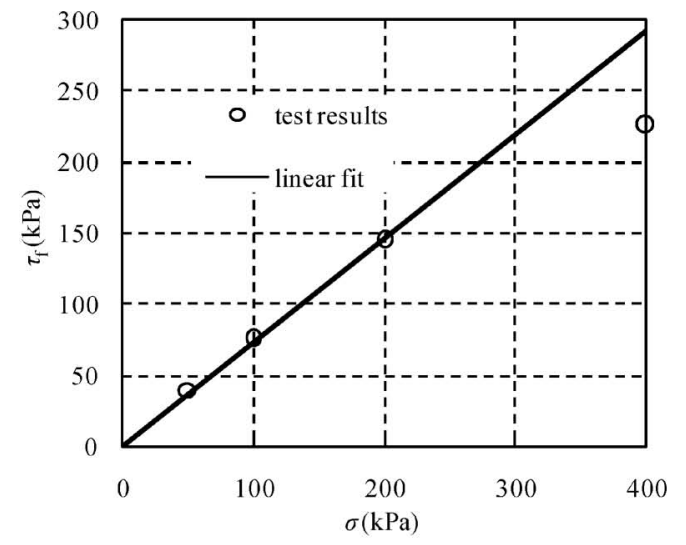

(b) residue strength

Fig. 6. Shear strength based on direct shear test. $\tau_{\mathrm{f}}$, shear strength; $\sigma$, normal stress

high normal stress.

The normal displacement decreased after a small increase if the normal stress was small (e.g., 50 or $100 \mathrm{kPa}$ ) but gradually increased if normal stress was large (e.g., $400 \mathrm{kPa}$ ). Thus, volumetric change due to dilatancy was significantly influenced by the magnitude of normal stress, similarly to a steel-gravelly soil interface (Zhang and Zhang, 2006b). In addition, the normal displacement significantly changed when shear stress had become steady, demonstrating that tangential displacement and volumetric change may have different deformation mechanisms due to shear application.

In this paper, peak shear strength is defined as the maximum shear stress, and residue strength is defined as the stable shear stress due to monotonic shear application under constant normal stress condition. Thus, a plot of shear strength versus normal stress (Fig. 6) was obtained according to the stress-displacement relationship (Fig. 5). The peak shear strength was nearly proportional to normal stress (Fig. 6(a)), similarly to a steel-gravel interface (Zhang and Zhang, 2006b). Therefore, peak shear strength, $\tau_{\mathrm{f}}$, can be formulated using Mohr-Coulomb strength criteria with only one parameter, friction angle, $\varphi$. That is, 


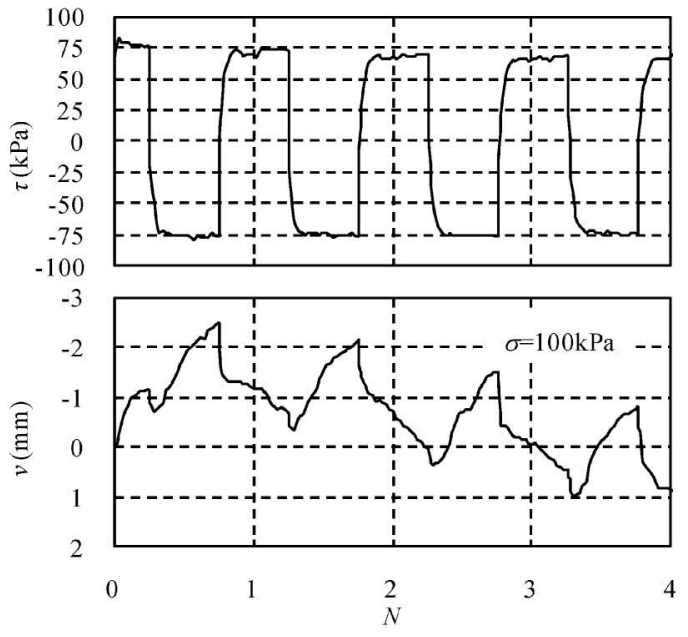

(a) $\sigma=100 \mathrm{kPa}$

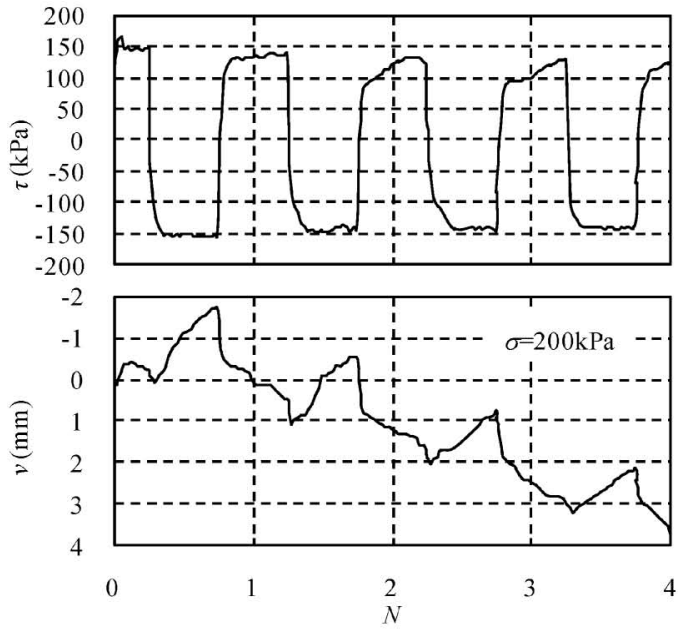

(b) $\sigma=200 \mathrm{kPa}$

Fig. 7. Cyclic stress and displacement histories of shear test results under constant normal boundary condition. $\tau$, shear stress; $\sigma$, normal stress; $u$, tangential displacement; $v$, normal displacement; $N$, number of shear cycles

$$
\tau_{\mathrm{f}}=\sigma \cdot \tan \varphi
$$

where $\sigma$ is the normal stress. The residue strength can also be formulated using a line approximately; however, the derivation became significant when the normal stress increased to $400 \mathrm{kPa}$ (Fig. 6(b)).

\section{Cyclic Stress-displacement Relationship}

Figures 7 and 8 show the stress-displacement responses of the interface due to a two-way tangential displacement application. The plot of shear stress versus tangential displacement looked nearly closed within a single shear cycle but differed with different numbers of shear cycles (Fig. 8). The strain-softening behavior due to cyclic shear application was negligible after the first monotonic shear. The normal displacement accumulated in a whole with increasing number of shear cycles, but well-regulated varied within a single shear cycle (Fig. 7). When shear direc-
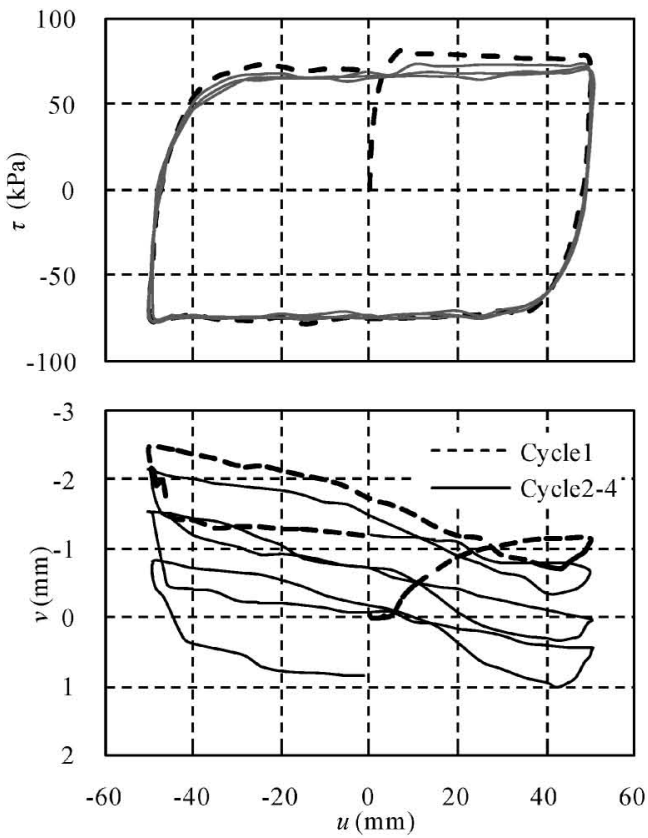

(a) $\sigma=100 \mathrm{kPa}$
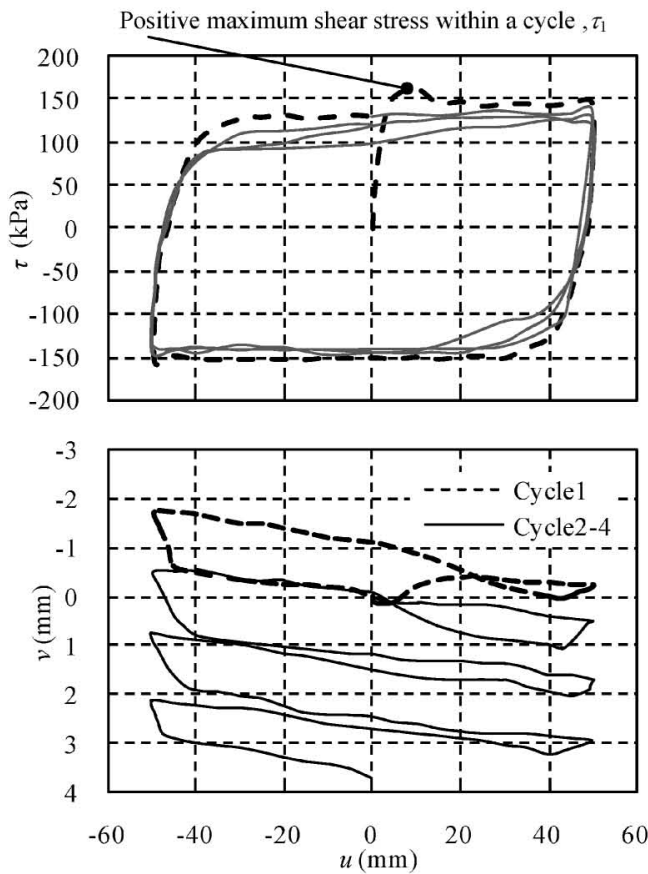

(b) $\sigma=200 \mathrm{kPa}$

Fig. 8. Cyclic stress-displacement relationship of shear test results under constant normal boundary condition. $\tau$, shear stress; $\sigma$, normal stress; $u$, tangential displacement; $v$, normal displacement

tion was reversed, the normal displacement always increased. This response exhibited a trend similar to the behavior of a steel-gravel interface (Zhang and Zhang, 2006b).

There was an asymmetric response of stress and displacement in different shear directions of the interface due to a symmetrical tangential displacement application 


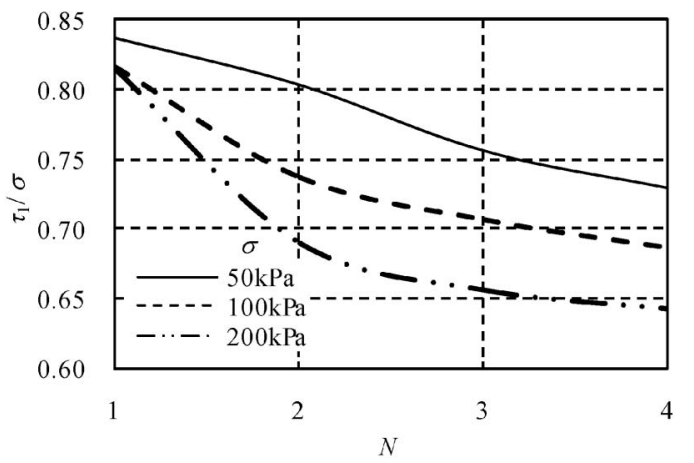

Fig. 9. Stress ratio change due to cyclic shear application. $\tau_{1}$, peak positive shear stress within a cycle; $\sigma$, normal stress; $N$, number of shear cycles

(Fig. 8). For example, shear stress had a smaller absolute maximum value in the initial shear direction than in the reverse direction; the normal displacement showed more significant asymmetry in different shear directions. In particular, normal displacement tended to increase after a small compression due to unloading, if tangential displacement was applied in the initial shear direction; while there was a tendency to decrease in the reverse direction. This inconsistency of the stress-displacement relationship in different shear directions has previously been described as "aeolotropy of interface", based on results of a steelgravel interface (Zhang and Zhang, 2006b).

The maximum shear stress within a single shear cycle decreased a little with increasing number of shear cycles if the normal stress was maintained (Figs. 7 and 8). The decrease extent of stress ratio in the monotonic shear direction (i.e., shear strength) increased significantly with increasing normal stress (Fig. 9). This strength behavior was significantly different from that of a steel-gravel interface, where friction angle was maintained with increasing number of shear cycles (Zhang and Zhang, 2006b).

\section{Microscopic Observations and Measurements}

The photographs of the geotextile and adjacent soil at the initial state and fourth shear cycles indicated that significant crushing of soil particles near the geotextile appeared due to the application of cyclic shear (Fig. 10). The particle crushing was also found in the tests of the steel-gravel interface, especially under cyclic shear conditions (Zhang and Zhang, 2006b). In addition, the structure plate with geotextile went down gradually as a whole with increasing number of shear cycles shown in the photographs (Fig. 10) and measured changes in the normal displacement using the transducers (e.g., Fig. 7). This demonstrates that some compression of soil near the geotextile was induced by shear application. Therefore, there was significant physical state evolution of soil near the geotextile, including particle crushing and compression due to shear application, similar to a steel-gravel interface (Zhang and Zhang, 2006b). Moreover, rather than the steel-gravel interface, the damage to geotextile should be involved to the evolution of the physical state of the interface. These physical evolutions in turn changed the

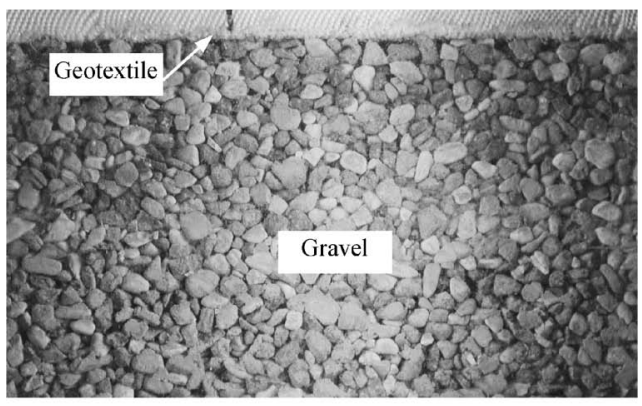

(a) initial state

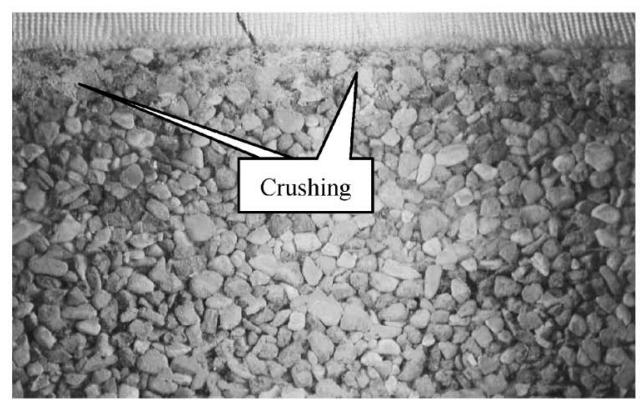

(b) 4 th cycle

Fig. 10. Photographs of the geotextile and soil nearby during a cyclic shear test under constant normal stress of $200 \mathrm{kPa}$. The loading conditions are as Fig. 7

stress-displacement relationship response. For example, the particle crushing may cause the decrease of shear strength of the interface (Zhang and Zhang, 2006b).

A series of high resolution digital photographs taken through the transparent lucite window, recorded the geotextile and adjacent soil during testing. Characterized using a line segment with a few tracing points, a soil particle can be tracked by finding the corresponding position of tracing points on the line segment in a series of photographs (Zhang et al., 2006). The movement of a soil particle was obtained by the translation of the midpoint of the segment and rotation angle of the soil particle from that of the segment.

Figure 11 shows a typical measurement of soil particle movements near the geotextile. The horizontal translation was defined as positive if in the same direction as the soil container, while vertical translation was positive if downward and the rotation was positive if clockwise (Fig. 11(a)). The horizontal translations of soil particles were always opposite to the movement direction of the soil container (Fig. 11). The horizontal translations relative to the soil container appeared in the zone close to the geotextile; they decreased with increasing distance from the geotextile and were negligible by $40 \mathrm{~mm}$ from the geotextile. These horizontal translations increased with increasing tangential displacement, yet were always less than the tangential displacement of the soil container (Fig. 11). This demonstrates that tangential displacement of the interface was induced not only by slippage between the geotextile and adjacent soil at the contact surface, but also by deformation of the soil constrained by the geotextile. The 

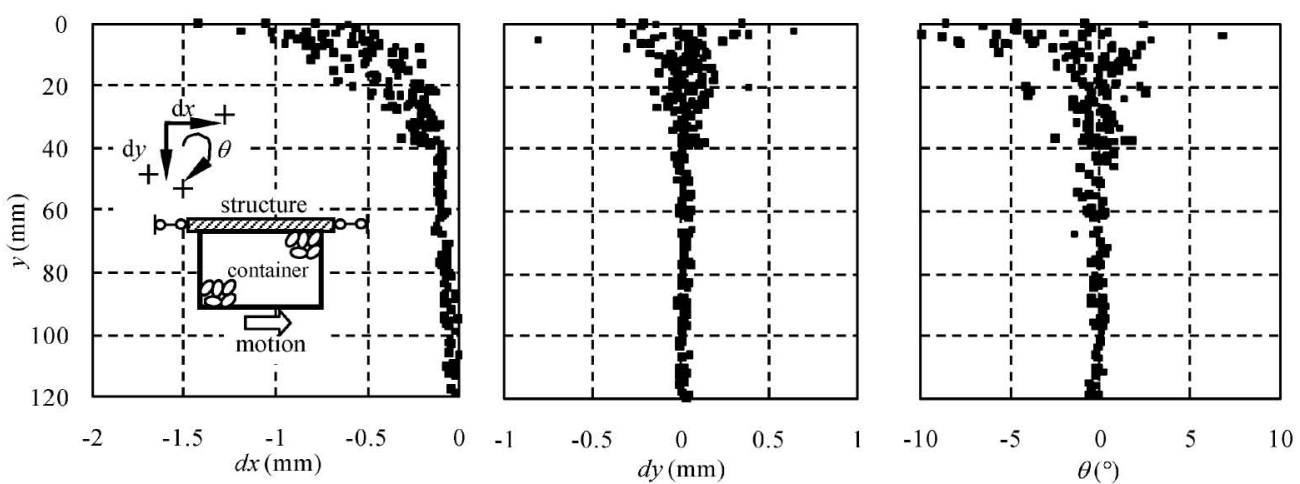

(a) tangential displacement of the interface is $3.1 \mathrm{~mm}$
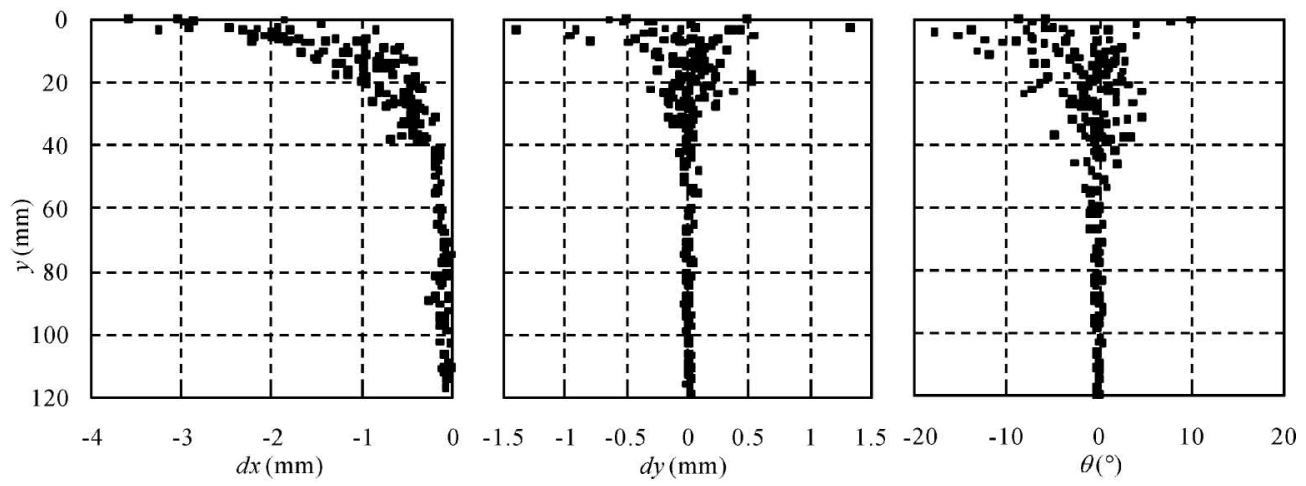

(b) tangential displacement of the interface is $9.2 \mathrm{~mm}$

Fig. 11. Soil particle movements relative to the soil container during a monotonic shear test under constant normal stress of $200 \mathrm{kPa}$. Data point, movements of an individual soil particle; $y$, distance from the geotextile; $d x$, horizontal movement; $d y$, vertical movement; $\theta$, rotation

vertical translations and rotations of soil particles appeared in a complex way but exhibited quite significant regularity as a whole (e.g., Fig. 11). For example, the majority of soil particles rotated anticlockwise due to the constraint of the geotextile. Thus, the deformation of the soil due to constraint of the geotextile was the main contribution to volumetric change due to dilatancy, as has been discovered on a steel-gravel interface (Zhang and Zhang, 2006b). In addition, it is possible that the main reason for "aeolotropy of interface" was that the initial monotonic shear application caused structural aeolotropy of arrangement and dip direction of soil particles near the geotextile (Fig. 11).

The measurements showed that there were significant movements of soil particles only in a narrow zone close to the geotextile, demonstrating the interface thickness. From the measurements (Fig. 11), the interface thickness was estimated at 5-6 times the average soil grain size (i.e., about $40 \mathrm{~mm}$ ), similar to the steel-gravel interface (Zhang and Zhang, 2006b).

\section{PULLOUT TEST RESULTS}

Large-scale pullout tests were conducted on the geotextile with the gravel on both sides under different normal stress conditions. It should be noted that the geotextile was ruptured during the pullout test when normal
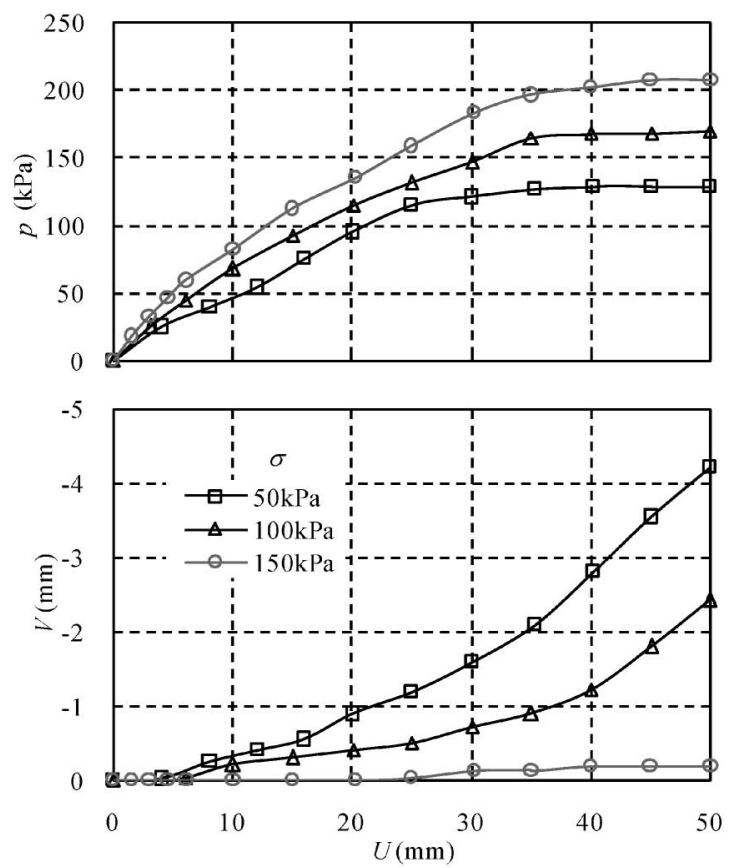

Fig. 12. Geotextile pullout test results with the gravel on both sides. $p$, average shear resistance; $U$, pullout displacement; $V$, normal displacement; $\sigma$, normal stress 
stress was $200 \mathrm{kPa}$; thus the results are presented only to $150 \mathrm{kPa}$ of normal stress. Figure 12 shows the change process of the "average shear resistance" and normal displacement with increasing pullout displacement. There the "average shear resistance" is based on the average sense to be consistent with the normal stress; it is equal to the total pullout force divided by the area of the contact zone between the geotextile and gravel. Compared with the direct shear test results (Fig. 5), there were significant differences in the pullout tests, including: (1) The relationship curve between average shear resistance and pullout displacement was significantly flatter than the one obtained from the direct shear test. For example, average shear resistance became stable when pullout displacement reached $40 \mathrm{~mm}$ while shear stress became stable only when tangential displacement reached $15 \mathrm{~mm}$ at normal stress of $100 \mathrm{kPa}$. (2) The normal displacement became significant only when pullout displacement increased to a certain value; this pullout displacement was far larger than the one in the shear test. This can be contributed to low tensile modulus of the geotextile, which caused significant deformation of the geotextile itself. Therefore, the pullout displacement consisted of evident deformation of the geotextile. It should be noted that the deformation of the geotextile included that of the $50 \mathrm{~mm}$-long geotextile that did not contact the soil. It can be concluded that the relative movement on the contact surface between the soil and geotextile occurred progressively during the pullout test and was significantly less than the apparent pullout displacement. In other words, the shear stress of the interface transferred progressively from load end to the free end; a larger pullout displacement was needed to reach the peak value.

The interpretation of pullout tests underestimated the shear stiffness of the interface, similarly to a clay-geotextile interface (Long et al., 2007). In this sense, the relationship of the average shear resistance versus pullout displacement does not accurately describe the stressstrain relationship of the interface. However, it can provide more realistic simulation of behavior of such an interface because the deformation of the geotextile can be involved.

The rotations of several typical soil particles near the geotextile were measured using image analysis (Fig. 13). These soil particles exhibited significant rotations when pullout displacement exceeded $10 \mathrm{~mm}$, and the soil particles near the load end rotated earlier than those near the free end. This indicated that a soil particle' rotation required a certain pullout displacement, consistent with the change rule of normal displacement.

When the average shear resistance reached an approximately stable state, it can be derived that the deformation of the geotextile also became stable because the pullout force was maintained. We conclude that shear stress at the interface became uniform at this time, with only relative displacement between the geotextile and soil. Thus, the stable value of average shear resistance can be regarded as the shear strength of the interface under pullout test conditions; it may be closer to twice the residue

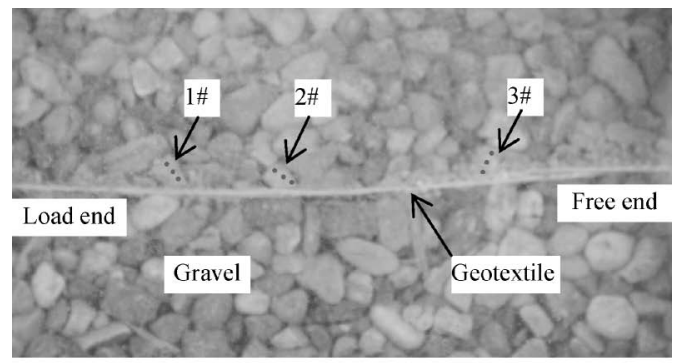

(a) photograph at initial state

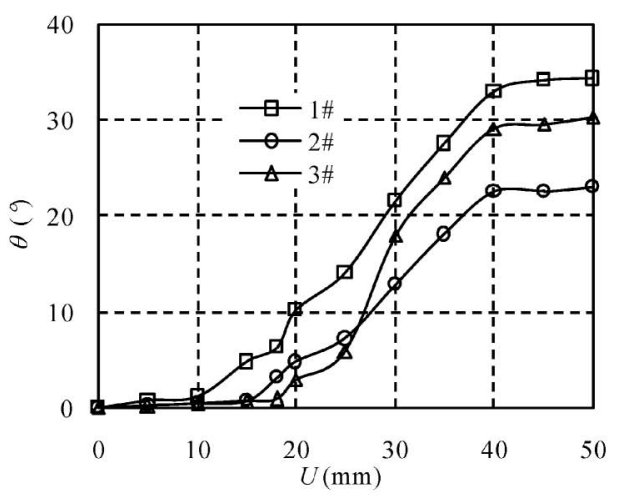

(b) rotation of soil particles

Fig. 13. Microscopic measurement results of geotextile pullout test with the gravel on both sides under constant normal stress of $\mathbf{5 0}$ kPa. $U$, pullout displacement; $\theta$, rotation

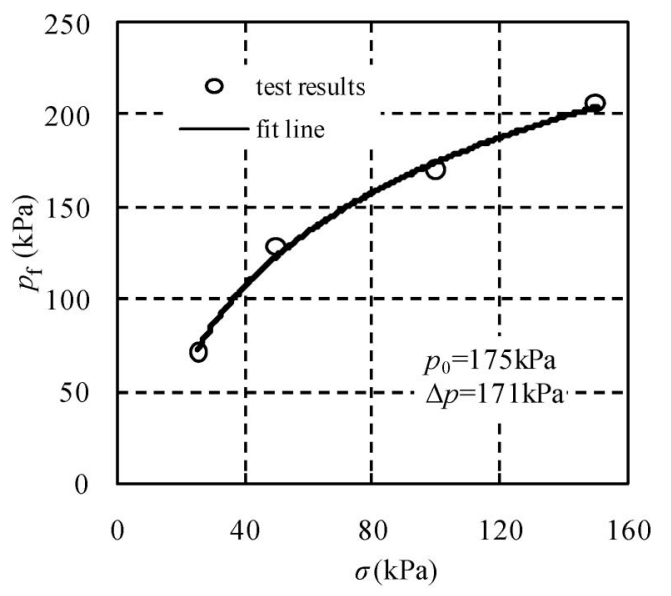

Fig. 14. Shear strength based on the geotextile pullout test results with the gravel on both sides. $p_{\mathrm{f}}$, pullout strength; $\sigma$, normal stress

strength of direct shear tests because of two contact surfaces in pullout tests. Such the strength is defined as "pull strength," denoted as $p_{\mathrm{f}}$, to distinguish from the strength from direct shear tests. In pullout tests, the pull strength increased with increasing normal stress in a nonlinear relationship (Fig. 14); moreover, it was significantly more than twice the residue shear strength of direct shear tests under small normal stress conditions (e.g., $50 \mathrm{kPa}$ ) (Fig. 6).

This strength behavior from pullout tests can be ex- 

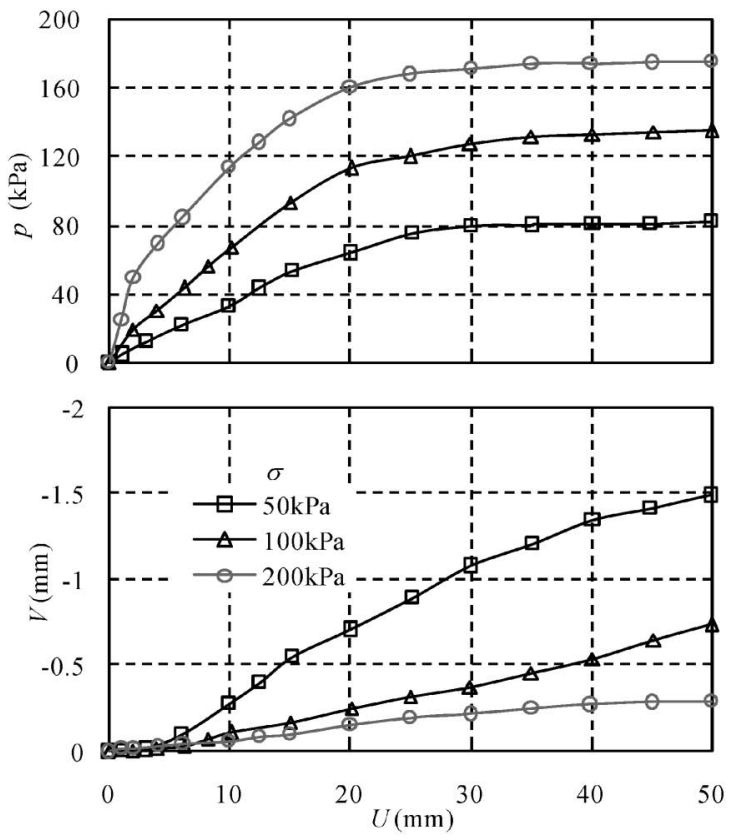

Fig. 15. Geotextile pullout test results with the gravel on one side. $p$, average shear resistance; $U$, pullout displacement; $V$, normal displacement; $\sigma$, normal stress

plained as follows. The interface exhibited significant dilatancy under low normal stress conditions (Fig. 5), which led to many small local protuberances on the soilgeotextile interface due to flexibility of the geotextile. Thus, the soil-geotextile contact area increased significantly requiring a larger pullout force. In other words, shear strength of the interface increased due to dilatancy. This explanation is supported by the large negative normal displacement (i.e., dilative volumetric change) when normal stress was small (Fig. 12). Increasing normal stress significantly decreased the dilatancy of the interface, for example, the negative normal displacement was significantly small when normal stress was $150 \mathrm{kPa}$ (Fig. 12); thus shear strength due to dilatancy decreased correspondingly.

A logarithmic equation was used to describe the nonlinear relationship between the pullout strength, $p_{\mathrm{f}}$, and normal stress, obtained from pullout tests, as follows:

$$
p_{\mathrm{f}}=p_{0}+\Delta p \log \left(\frac{\sigma}{p_{\mathrm{a}}}\right)
$$

where $p_{\mathrm{a}}$ is the standard atmosphere. $p_{0}$ and $\Delta p$ are the parameter; they are set to $175 \mathrm{kPa}$ and $171 \mathrm{kPa}$ according to the test results, respectively. This function showed a good fit to the test results when normal stress was not more than $150 \mathrm{kPa}$ (Fig. 14).

Another group of pullout tests were conducted with gravel on one side of the geotextile and sand on the other. The relationship between the average shear resistance and pullout displacement showed that the dilatancy extent decreased significantly when gravel was replaced with sand on one side (Fig. 15). Accordingly, there was a significant decrease in the nonlinear extent of the relationship between the pull strength and normal stress (Fig.

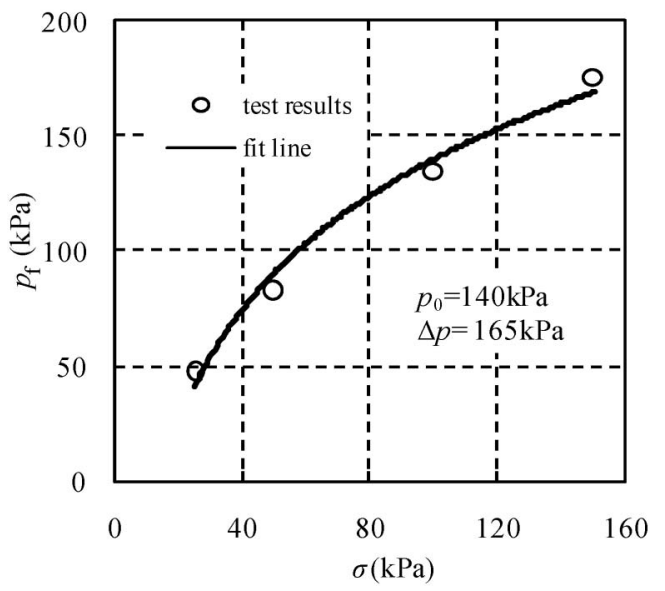

Fig. 16. Shear strength based on the geotextile pullout test results with the gravel on one side. $p_{\mathrm{f}}$, pullout strength; $\sigma$, normal stress

16). It may be because that the sand particles were fairly small and so local protuberances were weakened accordingly. The logarithmic equation adequately fitted the relationship between shear strength and normal stress of such pullout tests (Fig. 16). This demonstrates that the relationship between the pullout strength and normal stress can be described by using an isomorphic expression.

\section{DISCUSSION}

The direct shear and pullout tests are the two most widely-used approaches to investigate the behavior of soil-geotextile interfaces. However, the test results in the present paper show that these two types of test methods yield significantly different responses because pullout tests allows for significant deformation of geotextile, compared with the relative displacement on the interface. The direct shear test can give an entire stress-displacement relationship, but it is difficult to simulate shear strength due to dilatancy induced by raised contact areas during shearing. The pullout test can consider the deformation of the geotextile itself and is closer to practical situations. However, the stress and deformation are significantly nonuniform on the interface during pullout tests; they can be regarded as uniform only when a stable pullout force is achieved.

Therefore, neither direct shear nor pullout tests give comprehensive understanding of the behavior of the interface between a geotextile and gravelly soil. Therefore, the appropriate test method should be selected with careful consideration of the site conditions of the interface. Combining both test methods seems an effective approach for investigation of the interfaces.

\section{CONCLUSIONS}

A series of large-scale direct shear and pullout tests were conducted to investigate the monotonic and cyclic behavior of a gravel-geotextile interface. On the basis of 
the macro- and micro- observation results, the main behaviors of the interface are discovered or summarized as follows:

(1) The interface exhibited significant strain-softening due to damage to the geotextile during shearing; the softening extent was significantly influenced by normal stress. The shear strength from the direct shear test was proportional to normal stress and decreased with increasing number of shear cycles.

(2) The normal displacement accumulated as a whole with increasing number of shear cycles, but varied within a single shear cycle in a well-regulated manner in cyclic shear tests and was dependent on shear direction. The change of normal displacement was significantly influenced by normal stress.

(3) Shear deformation of the interface was composed of slippage on the contact surface and deformation of the soil constrained by the geotextile; the volumetric change due to dilatancy was induced mainly by the latter. The thickness of the interface was estimated at 5-6 times the average soil grain size. There was significant evolution of physical state due to shear application, including soil particle crushing and soil compression as well as damage to the geotextile.

(4) The relative movement at the contact surface between the soil and geotextile occurred progressively in the pullout test because the geotextile had significant deformation of its own. Thus, shear stiffness of the interface was underestimated.

(5) Rather than direct shear tests, the pullout tests showed that shear strength of the interface increased with increasing normal stress by a nonlinear relationship due to dilatancy, described by a logarithmic relationship.

(6) Neither direct shear nor pullout tests can give comprehensive understanding of the behavior of the interface between a geotextile and gravelly soil. An appropriate test method should be selected with careful consideration of the site conditions.

\section{ACKNOWLEDGEMENTS}

The project is supported by National Basic Research Program of China (973 Program) (No. 2007CB714108) and National Natural Science Foundation of China (No. 50679034, 50778105).

\section{REFERENCES}

1) Abu-Farsakh, M., Coronel, J. and Tao, M. (2007): Effect of soil moisture content and dry density on cohesive soil-geosynthetic interactions using large direct shear tests, Journal of Materials in Civil Engineering, 19(7), 540-549.

2) Aiban, S. A. and Ali, S. M. (2001): Nonwoven geotextilesabkhaand-sand interface friction characteristics using pullout tests, Geosynthetics International, 8(3), 193-220.

3) Athanasopoulos, G. A. (1996): Results of direct shear tests on geotextile reinforced cohesive soil, Geotextiles and Geomembranes, 14(11), 619-644.
4) Bakeer, R. M., Abdel-Rahman, A. H. and Napolitano, P. J. (1998): Geotextile friction mobilization during field pullout test, Geotextiles and Geomembranes, 16(2), 73-85.

5) Eigenbrod, K. D., Burak, J. P. and Locker, J. G. (1990): Differential shear movements at soil-geotextile interfaces, Canadian Geotechnical Journal, 27(4), 520-526.

6) Fannin, R. J. and Raju, D. M. (1993): On the pullout resistance of geosynthetics, Canadian Geotechnical Journal, 30(3), 409-417.

7) Giroud, J. P., Darrasse, J. and Bachus, R. C. (1993): Hyperbolic expression for soil-geosynthetic or geosynthetic-geosynthetic interface shear strength, Geotextiles and Geomembranes, 12(3), 275-286.

8) Gourc, J. P. and Ramirez, R. R. (2004): Dynamics-based interpretation of the interface friction test at the inclined plane, Geosynthetics International, 11(6), 439-454.

9) Guler, M., Edil, T. B. and Bosscher, P. J. (1999): Measurement of particle movement in granular soils using image analysis, Journal of Computing in Civil Engineering, 13(2), 116-122.

10) Lee, K. M. and Manjunath, V. R. (2000): Soil-geotextile interface friction by direct shear tests, Canadian Geotechnical Journal, 37(1), 238-252.

11) Lima, J., Palmeira, E. M. and Mello, L. G. R. (2002): Interaction between soils and geosynthetic layers in large-scale ramp tests, Geosynthetics International, 9(2), 149-187.

12) Ling, H. I., Burke, C., Mohri, Y. and Matsushima, K. (2002): Shear strength parameters of soil-geosynthetic interfaces under low confining pressure using a tilting table, Geosynthetics International, 9(4), 373-380.

13) Lo, S. R. (2003): The influence of constrained dilatancy on pullout resistance of strap reinforcement, Geosynthetics International, 10(2), 47-55.

14) Long, P. V., Bergado, D. T. and Abuel-Naga, H. M. (2007): Geosynthetics reinforcement application for tsunami reconstruction: Evaluation of interface parameters with silty sand and weathered clay, Geotextiles and Geomembranes, 25(4-5), 311-323.

15) Lopes, P. C., Lopes, M. L. and Lopes, M. P. (2001): Shear behaviour of geosynthetics in the inclined plane test-Influence of soil particle size and geosynthetic structure, Geosynthetics International, 8(4), 327-342.

16) Saleh, N. M. (2001): Experimental evaluation of soil-geotextile interface friction properties, Journal of Engineering and Applied Science, 48(3), 419-435.

17) Stark, T. D. and Poeppel, A. R. (1994): Landfill liner interface strengths from torsional-ring-shear tests, Journal of Geotechnical Engineering, 120(3), 597-617.

18) Stoewahse, C., Dixon, N., Jones, D. R. V., Blumel, W. and Kamugisha, P. (2002): Geosynthetic interface shear behaviour: Part 1 test methods, Ground Engineering, 35(2), 35-41.

19) Swan, R. H. Jr. (1987): Influence of fabric geometry on soil/geotextile shear strength, Geotextiles and Geomembranes, 6(1-3), 81-87.

20) Tan, S. A, Muhammad, N. and Karunaratne, G. P. (1995): Adhesion at jute geotextile/clay slurry interface, Soils and Foundations, 35(3), 15-22.

21) Tan, S. A., Chew, S. H. and Wong, W. K. (1998): Sand-geotextile interface shear strength by torsional ring shear tests, Geotextiles and Geomembranes, 16(3), 161-174.

22) Uesugi, M. and Kishida, H. (1986): Frictional resistance at yield between dry sand and mild steel, Soils and Foundations, 26(4), 139-149.

23) Zhang, G. and Zhang, J.-M. (2006a): A large-scale apparatus for monotonic and cyclic soil-structure interface test, Geotechnical Testing Journal, 29(5), 401-408.

24) Zhang, G. and Zhang J.-M. (2006b): Monotonic and cyclic tests of interface between structure and gravelly soil, Soils and Foundations, 46(4), 505-518.

25) Zhang, G., Liang, D. and Zhang J.-M. (2006): Image analysis measurement of soil particle movement during a soil-structure interface test, Computers and Geotechnics, 33(4-5), 248-259. 